\title{
Bumble bee species' responses to a targeted conservation measure depend on landscape context and habitat quality
}

\author{
C. Carvell, ${ }^{1}$ J. L. Osborne, ${ }^{2}$ A. F. G. Bourke, ${ }^{3}$ S. N. Freeman, ${ }^{1}$ R. F. Pywell,${ }^{1}$ and M. S. Heard ${ }^{1,4}$ \\ ${ }^{1}$ NERC Centre for Ecology and Hydrology, Maclean Building, Crowmarsh Gifford, \\ Wallingford, Oxfordshire OX108BB United Kingdom \\ ${ }^{2}$ Rothamsted Research, Harpenden, Hertfordshire AL52JQ United Kingdom \\ ${ }^{3}$ School of Biological Sciences, University of East Anglia, Norwich NR4 7TJ United Kingdom
}

\begin{abstract}
The global decline of insect pollinators, especially bees, is cause for concern, and there is an urgent need for cost-effective conservation measures in agricultural landscapes. While landscape context and habitat quality are known to influence species richness and abundance of bees, there is a lack of evidence from manipulative field experiments on bees' responses to adaptive management across differently structured landscapes. We present the results of a large-scale study that investigated the effects of a targeted agri-environment scheme (AES) on bumble bees (Bombus spp.) over three years in the United Kingdom. Forage patches of different sizes were sown with a conservation flower mixture across eight sites covering a broad range of agricultural land use types. Species richness and worker densities (especially of the longer-tongued Bombus species for which the mixture was targeted) were significantly higher on sown forage patches than on existing non-crop control habitats throughout the three-year study, but the strength of this response depended on both the proportions of arable land and abundance of herbaceous forb species in the surrounding landscape. The size of sown patches also affected worker density, with smaller patches $(0.25$ ha) attracting higher densities of some species than larger patches (1.0 ha). Our models show that a targeted AES can deliver greater net benefits in more intensively farmed areas, in terms of the number and species richness of bumble bees supported, than in heterogeneous landscapes where other foraging habitats exist. These findings serve to strengthen the evidence base for extending agri-environment schemes to boost declining pollinator populations to a larger number of agricultural landscapes across the globe.
\end{abstract}

Key words: agri-environment schemes; bee conservation; Bombus spp.; forage plants; habitat quality; land use; pollinators; United Kingdom.

\section{INTRODUCTION}

Agricultural intensification and land use change have been major drivers of worldwide losses of biodiversity over recent decades (Tilman et al. 2001). These changes can be considered at different spatial scales (Tscharntke et al. 2005). At the landscape scale, increases in field size and reductions in mixed farming have resulted in simplified landscapes with little non-crop area. At the local scale, intensification of resource use and increasing inputs such as fertilizers have led to the simplification of remaining seminatural habitats with effects for many taxa (Robinson and Sutherland 2002). Understanding how different taxa are influenced by landscape context and local habitat quality has considerable implications for their conservation and management of the ecosystem services they provide (Steffan-Dewenter et al. 2002, Kremen et al. 2007, Ricketts et al. 2008, Keitt 2009). Still lacking, however, is evidence from manipulative field

Manuscript received 1 April 2010; revised 5 October 2010; accepted 8 November 2010. Corresponding Editor: M. P. Ayres.

${ }^{4}$ Corresponding author. E-mail: mshe@ceh.ac.uk experiments on the effects of adaptive management strategies for conserving biodiversity across differently structured landscapes (but see Heard et al. 2007). In this paper we address this question directly using a threeyear study of the effects on bumble bees of a targeted agri-environment scheme recently adopted in England, United Kingdom.

Bumble bees (Bombus spp.) are a group of pollinating insects that has been highly susceptible to the effects of intensive agriculture (Winfree et al. 2009). Across Europe and North America, many bumble bee species have shown declines in abundance and contractions in range since the mid-20th century (Williams 1982, Grixti et al. 2009, Williams and Osborne 2009). Many of the declining species in Europe are among the longertongued bumble bees, which tend to specialize on plant species with long corollae, such as the legumes (Fabaceae) that produce high protein pollens (Goulson et al. 2005, Hanley et al. 2008). Analyses of historical plant distribution data sets have revealed that a large proportion of bumble bee forage plant species (including the legumes Trifolium pratense and Lotus corniculatus) declined significantly during the 20th century, suggesting 
a causative link between bee declines and the loss of key nectar and pollen sources from European agricultural landscapes (Carvell et al. 2006, Kleijn and Raemakers 2008). These declines have economic as well as conservation implications, since bumble bees are important pollinators of entomophilous crops and of a large proportion of wild plant species (Corbet et al. 1991). Along with other wild bees, they may provide an insurance policy against current honey bee declines (Winfree et al. 2008).

Agri-environment schemes (AES) aim to reverse the negative effects of modern agriculture on biodiversity by compensating farmers for undertaking less intensive management within the crop and creating new habitats on uncropped land (European Economic Community regulation 2078/92; EEC 1992). The "Environmental Stewardship" (ES) scheme in England includes specific options targeted at pollinators, aiming to enhance the supply of pollen and nectar sources through the sowing of conservation flower mixtures at field margins (Natural England 2010a). One such option is the relatively low-cost "nectar flower mixture" (EF4 under the Entry Level Scheme [ELS]), which includes several leguminous species (e.g., T. pratense, T. hybridum, L. corniculatus, Onobrychis viciifolia). This has been shown to enhance significantly the local density and diversity of bumble bees on arable land when compared with conventional cropping or other less targeted ELS options (Pywell et al. 2006, Carvell et al. 2007). How much of this high quality foraging habitat is needed and how it should be distributed within agricultural landscapes is not yet known, and is a key question to address if the impact of government investment in such schemes is to be maximized across different regions (Lonsdorf et al. 2009). It is, however, recognized that both foraging behavior and population size in bumble bees are likely to be determined by patterns of resource availability at landscape, rather than local, scales (Knight et al. 2005, Osborne et al. 2008).

An increasing number of studies have demonstrated correlations between species richness and density of flower-visiting bees on focal plots and landscape context (Steffan-Dewenter et al. 2002, Westphal et al. 2003). It is also clear that farming systems can interact with landscape context to determine local bee diversity, such that, for example, organic farming has a stronger positive effect on bee diversity in homogeneous landscapes (Holzschuh et al. 2007, Rundlöf et al. 2008). However, while it has been proposed that conservation measures promoting the sowing of flower mixtures should focus on more intensively farmed (though not highly simplified) landscapes (Tscharntke et al. 2005, Isaacs et al. 2009), there is no experimental evidence for this. Importantly, any effects of sown flower mixtures need to be assessed relative to existing resources supplied by natural vegetation in conventionally managed control areas (Kleijn et al. 2006).
In this study, we used a targeted AES for pollinators (the ELS nectar flower mixture option), implemented across eight sites in central and eastern England, United Kingdom, selected to cover a broad range of agricultural land use types, to address three objectives: (1) to determine the response of foraging bumble bees to sown forage patches and whether this is consistent over time; (2) to determine whether the density of foraging bumble bees is related to the size of sown patches, and (3) to investigate the influence of landscape context and habitat quality on the response of different bumble bee species to this targeted AES option. We measured the "response" as the density of bumble bee workers and species on sown forage patches vs. control areas, and incorporated flower density of visited forage plants into our analyses to account for the influence of variations in forage density on numbers of bees observed. This work builds on a previous study by the authors (Heard et al. 2007) but importantly adds data collected over three years and includes an intensive survey of fine-scale floral resources and landscape composition, both of which have been shown to be critical in developing models from which to design strategic adaptive management plans for pollinators (Lonsdorf et al. 2009). To our knowledge no other study has taken such a large-scale experimental approach to addressing the effects of an agri-environment scheme on any invertebrate taxon.

\section{Methods \\ Experimental design and study sites}

We selected eight farms across central and eastern England, located between $1^{\circ} 40^{\prime} \mathrm{W}$ and $1^{\circ} 02^{\prime} \mathrm{E}$ longitude and between $51^{\circ} 10^{\prime}$ and $52^{\circ} 56^{\prime} \mathrm{N}$ latitude, that represented typical land use for their locations but varied widely in landscape characteristics (Table 1; Appendix A). At each farm (henceforth "site"), three patches of different sizes $(0.25,0.5$, and 1.0 ha) were sown with a mixture of $20 \%$ legumes (Trifolium pratense of early and late flowering varieties, Trifolium hybridum and Lotus corniculatus) and $80 \%$ fine-leaved grasses (Festuca rubra, Poa pratensis, and Cynosurus cristatus) (henceforth "sown patches"). We also selected a control patch of 0.25 ha representing typical non-crop vegetation for the site. Each patch was randomly allocated along a field edge or corner, and the four patches at a site were separated by $\sim 3 \mathrm{~km}$ (mean distance from nearest neighboring patch $=2.99 \mathrm{~km}$ ) to minimize the influence of bumble bee dispersal between them (Knight et al. 2005).

Sown patches were established in September 2003 to achieve consistent flowering by summer 2005, when our bee survey began. The legume and grass seed mixture was sown onto a fine seedbed at a rate of $20 \mathrm{~kg} / \mathrm{ha}$ and subsequently no fertilizers or herbicides were applied. Once established, patches were cut to a height of $10 \mathrm{~cm}$ twice during the first year (2004) in April and September and thereafter once in September each year. By the summer of 2006, the sown grass species had begun to 
TABLE 1. Surveyed measures (percent cover) of landscape context and foraging habitat quality for each farm study site in central and eastern England.

\begin{tabular}{|c|c|c|c|c|c|c|c|}
\hline \multirow[b]{2}{*}{ Site } & \multicolumn{4}{|c|}{ Landscape context } & \multicolumn{3}{|c|}{ Foraging habitat quality } \\
\hline & $\begin{array}{l}\text { Arable } \\
\text { land }\end{array}$ & $\begin{array}{l}\text { Improved } \\
\text { grassland }\end{array}$ & $\begin{array}{l}\text { Built-up } \\
\text { areas }\end{array}$ & $\begin{array}{l}\text { Seminatural } \\
\text { habitat }\end{array}$ & $\begin{array}{l}\text { All } \\
\text { forbs }\end{array}$ & $\begin{array}{l}\text { Key forage } \\
\text { plants }\end{array}$ & MFC \\
\hline 1 & $5.4(81.4$ & $5.2(2.4-7.7)$ & $3.8(3$ & 4.4 & $4.0(1.9$ & $0.7(0.2-1.5)$ & $16.3(10.8-21)$ \\
\hline 2 & 80 & $6.6(2.7-1)$ & $-14.7)$ & & $1.5)$ & & \\
\hline 3 & $75.2(62.2-89.7)$ & $2.1(0.3-4.7)$ & $4.9(1.5-12.8)$ & 16.0 & $(9.1$ & $6.2(1.7-12.9)$ & $11.6(9-12.5)$ \\
\hline 4 & $74.2(66.2-82.9)$ & $8.2(2.6-15.6)$ & $7.7(4.9-14.4)$ & $7.5(3.9-11.1)$ & $10.7(4.8-20.3)$ & $1.7(0.8-2.9)$ & $7.0(3.1-12.1)$ \\
\hline 5 & $51.3(27.7-64.8)$ & $26.6(17.3-40.8)$ & $5.7(2.7-9.7)$ & $14.7(8.8-22.6)$ & $14.9(9.4-25.7)$ & $1.3(0.5-2.9)$ & $9.0(3.9-19.4)$ \\
\hline 6 & $35.2(17.9-70.2)$ & $25.7(15.1-43.5)$ & $5.1(2.1-10.3)$ & $33.4(9.7-64.3)$ & $38.4(23.7-47.6)$ & $26.4(9.4-34.5)$ & $6.5(0.6-12.7)$ \\
\hline 7 & $32.1(20.8-41.7)$ & $22.5(6.5-35.7)$ & $21.2(6.9-31.2)$ & $23.2(11.8-29.4)$ & $13.0(9.7-16.5)$ & $1.3(0.5-2.4)$ & $5.6(1.6-13.6)$ \\
\hline 8 & $14.6(7.7-20.5)$ & $62.9(53.2-70)$ & $3.8(1.9-6.2)$ & $16.5(11.8-19.6)$ & $27.9(26.7-29.8)$ & $9.8(8.6-11)$ & $3.0(1.5-4.8)$ \\
\hline
\end{tabular}

Notes: Values give mean and range (min-max) percent cover of each variable within $1000 \mathrm{~m}$ of sampled patches, averaged across all patches within a site $(n=4$ per site except for site 8 with $n=3)$. Arable land includes cropped fields with cereals, mass-flowering crops (MFC), and horticultural crops. Seminatural habitat includes woodland, unimproved grassland, and non-crop linear features such as field margins and hedgerows. MFCs include mainly winter oilseed rape (Brassica napus) and field beans (Vicia faba) sown at most sites, but also spring oilseed rape, linseed, potatoes, peas and other legumes, borage, and Phacelia, each sown only at certain sites; values for this variable represent average percentages across the three survey years.

dominate on several patches, reducing cover of the sown legume species. These patches were therefore reestablished in September 2006, this time with grasses excluded from the mixture and a small amount of the annual Centaurea cyanus $(2 \%)$ added to the legume mixture of T. pratense (early and late flowering, 60\%), T. hybridum (18\%), and L. corniculatus (20\%). The seed mixture failed to establish altogether on one of the 28 sown patches (the 0.25-ha patch at site 8), which was subsequently excluded from our analyses.

\section{Bumble bee and flowering plant surveys}

Bumble bee activity was recorded monthly from May to September over the three years 2005-2007. Foraging bumble bees were counted along two fixed $2 \times 100 \mathrm{~m}$ transects in the center of each patch, and the plant species on which each bee was foraging was noted. All true social Bombus species were recorded to species level where possible and separated into worker, male, and queen castes. As in previous surveys (Carvell et al. 2007), workers of the ecologically similar species Bombus terrestris and B. lucorum were recorded as a group, denoted $B$. terrestris agg., as they cannot be distinguished reliably in the field. For B. ruderatus, only melanic individuals were recorded to species level, due to the difficulty of separating banded individuals from $B$. hortorum in the field (Ellis et al. 2005). In this paper we focus on the data for workers only. Transect visits were carried out between 10:00 and 17:30 hours during dry weather when ambient temperature was above $13^{\circ} \mathrm{C}$ with at least $60 \%$ clear sky, or $17^{\circ} \mathrm{C}$ under any sky conditions.

Flower abundance on each visit was measured by identifying all flowering dicotyledonous species and scoring their flower abundance within $102 \times 10 \mathrm{~m}$ sections of each bee transect, within the following ranges: $1-5 ; 6-25 ; 26-200 ; 201-1000 ; 1001-4999$; and $5000+$ flower units (defined as a single flower or an umbel, spike, or capitulum on multi-flowered stems). Flower abundance was expressed as the midpoint value for each range (with a value of 12000 for the $5000+$ category), and summed across all sections of the transect, giving a monthly estimate of the density of flowering units per transect.

\section{Landscape context and habitat quality assessment}

A detailed habitat survey was undertaken to characterize the landscape surrounding each patch. In July 2004 all land parcels (defined areas of continuous land use) within $1000 \mathrm{~m}$ of the patch center were visited and categorized according to their broad land use type and habitat composition. This radius took account of the best available estimates of foraging range for the dominant Bombus species in our study (Knight et al. 2005, 2009). For grasslands, field boundaries, uncropped arable areas, and woodlands the percentage cover of herbaceous forbs within the parcel was recorded as well as the cover of plant taxa used by foraging bumble bees, at both species and family level (usage by bumble bees being taken from published sources; Carvell et al. 2006). For built-up areas (including gardens), percentage cover of forbs within the parcel was estimated as far as possible. For arable fields both the crop type and percentage forb cover beneath the crop were recorded as a measure of weediness. Crop types were reassessed in 2005, 2006, and 2007 to reflect changes in rotation, including from arable to grassland, but uncropped habitats were assumed not to undergo significant change during the study.

The field survey data were digitized onto a U.K. Ordnance Survey base map using Arc GIS software version 9.2 (ESRI; Environmental Systems Research Institute, Redlands, California, USA), allowing for edits in parcel location, shape, and size. Parcel attributes were then extracted to allow calculation of (1) the total area of each broad land use type (hereafter landscape context) and (2) the absolute area coverage of (a) all herbaceous forbs, (b) each forage plant species or family, (c) all key forage plants grouped, and (d) mass 
flowering crops (MFCs), hereafter all measures of foraging habitat quality, within a radius of $1000 \mathrm{~m}$ of the center of each patch (Table 1). Key forage plants were defined as the 20 most visited species across all sites during our study (Appendix B).

We used the proportion of arable land (cropped fields) as our key measure of landscape context for analyses, as this variable was significantly negatively correlated with proportions of improved grassland $(r=-0.84, P<$ $0.001)$, built-up areas $(r=-0.37, P=0.03)$, and seminatural habitats $(r=-0.66, P<0.001)(n=31$ patches). The accuracy of our surveyed measure of arable land was confirmed by correlation $(r=0.87, P<$ 0.001 ) with the proportion of arable land estimated from a computer-classified land cover map derived from satellite-based multispectral scanners (Land Cover Map 2000; available online). ${ }^{5}$

\section{Statistical analysis}

Of the potential total of 480 patch-sampling visits over three years, 30 sampling visits were missed due to either failure of sown species to establish (one patch), or cutting or resowing of patches in early September before the sampling visit (a total of 10 patches at five sites). These missed visits were identified as missing values in all analyses, though their expected values remain estimable from the statistical models.

\section{Bumble bee response to sown forage patches}

The data on bee worker and flower abundance were summed across both transects per patch in each month, to give measures of density per $400 \mathrm{~m}^{2}$. The number of species recorded across the two transects of each patch was accumulated for each month to give mean richness per $400 \mathrm{~m}^{2}$. A forage plant was defined as any species visited by bees during the study, and the summed flower abundance of these species was used as a measure of forage density. Changes in local forage density per 400 $\mathrm{m}^{2}$ between years were tested using ANOVA on data for all years with year, month, site, and patch type as factors. Differences in forage density were then tested for each year in turn, using ANOVA with month, site, and patch type (sown vs. control) as factors, and additionally with sown patch size categories $(0.25,0.5$, 1.0 ha, and 0 ha representing the control patch) replacing the binary patch type classification to test for differences in forage provision between sown patches of different sizes.

For the bee data, separate analyses were conducted on worker density of the four most abundant Bombus species. Counts of the rarer species were included only in calculations of Bombus species richness and the summed abundance of all species, designated "total Bombus." We used generalized linear models to determine: (1) the bumble bee response to sown forage patches; (2)

\footnotetext{
${ }^{5}\langle$ www.ceh.ac.uk $\rangle$
}

whether this response was consistent over time, and (3) if it varied according to study site and sown patch size. Analysis began with a maximal model which included year, survey month, site, and patch type (sown vs. control) as fixed effects. Possible spatial and temporal variation in the bee species' response was accounted for by adding two-way interactions of patch type with site and year. To account for variation due to differences in flower abundance over time and between patches, we added forage density as a covariate along with interactions allowing separate "slopes" for the relationship between worker density and forage availability in each year, month, and site.

Models were fitted assuming a Poisson distribution for the patch count totals with a log-link function used to relate their expected values to the predictors in the maximal model. An adjustment for overdispersion was added in cases where the Pearson chi-square statistic exceeded its associated degrees of freedom by more than twofold (Crawley 2005). Thereafter, terms were removed sequentially until only significant interactions and main effects $(P<0.05)$ remained in the minimal adequate model (MAM). For ease in tabulating degrees of freedom, the $F$ statistics conventionally evaluated in the presence of overdispersion were replaced by accurate chi-square approximations ( $\mathrm{Li}$ and Martin 2002). Having selected MAMs, we estimated bumble bee worker density and species density for a standardized amount of forage in order to illustrate differences in preference for sown vs. control patches over and above the influence of available forage. We did this by calculating predicted values for each site/year/month combination (including those missed in the actual survey) from the model for each species or group, with forage density fixed at 1000 flower units on each visit except where otherwise stated.

\section{Effects of forage patch size}

To test whether the size of the three sown patches had an effect on worker density and richness, we fitted additional models in which patch size $(0.25,0.5,1.0$ ha) replaced the binary patch type classification within the MAM. Each patch size model was tested against the equivalent model with identical effects at all sown patches. A statistically significant deterioration in fit therefore implies a difference between patches of different sizes. Predicted values were then calculated as before for each patch size.

\section{Effects of landscape context and foraging habitat quality}

Effects of landscape context and foraging habitat quality (in each of the three categories: total cover of all herbaceous forbs, cover of all key forage plants, and cover of MFCs) on worker density and species richness were tested using simple linear models with normally distributed errors and a log-link function. The predicted values representing mean worker density at 1000 flower units per $400 \mathrm{~m}^{2}$ were averaged across years, and across 

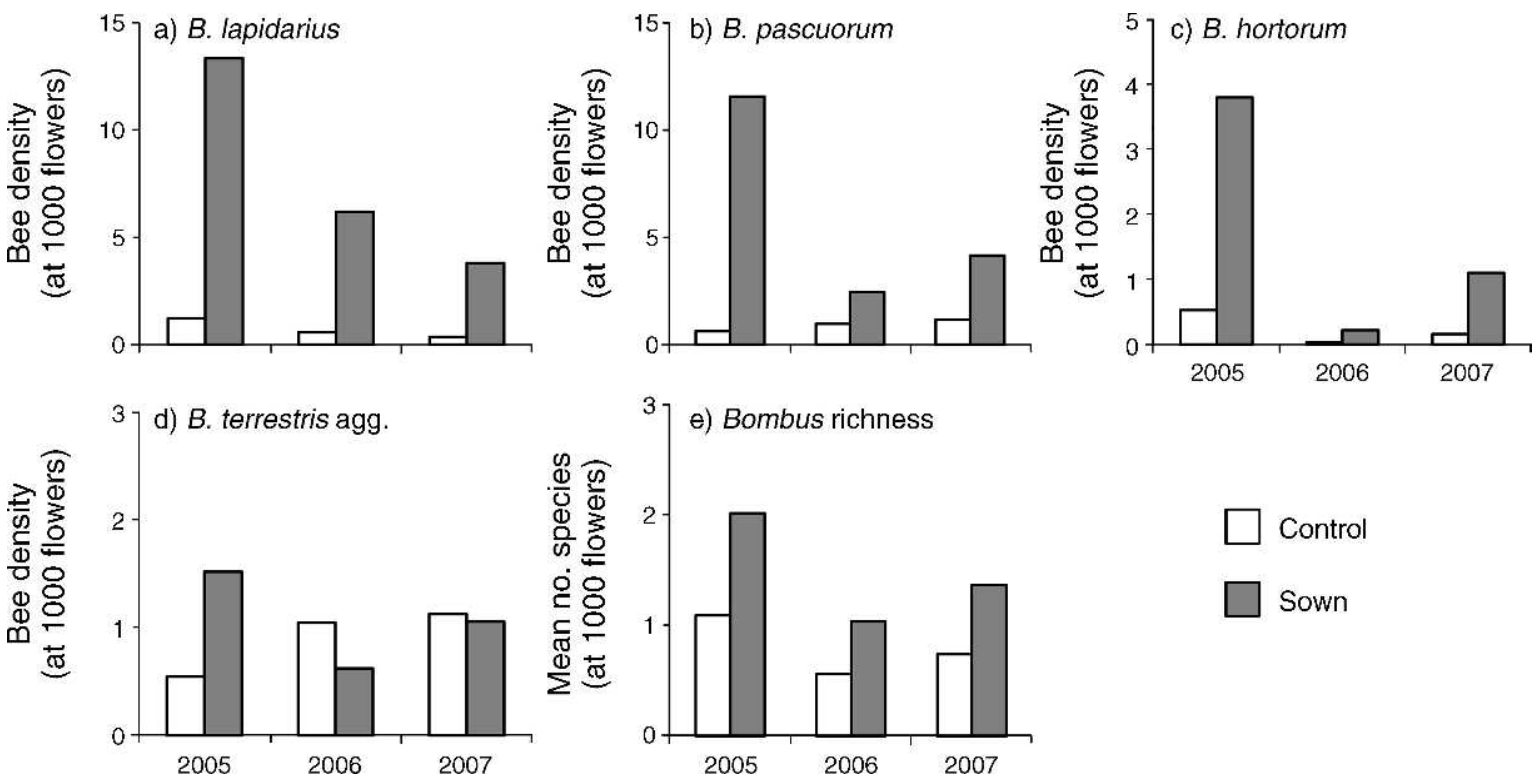

FIG. 1. Means of predicted values from minimal adequate models showing bumble bee worker density and species richness per $400 \mathrm{~m}^{2}$ on forage patches sown with a nectar flower mixture $(n=3$ patches per site) and control patches $(n=1$ patch per site) in each year. Predicted values were calculated with forage availability fixed at a constant level of 1000 flower units. There was no significant interaction between year and forage (Table 2); thus the predicted values increase in proportion with increases in forage availability, leaving the relative differences between years unchanged. The exception to this was B. lapidarius, in which the estimated proportional increase in predicted values with, for example, an increase in forage from 1000 to 10000 flowers was $11 \%$ in $2005,23 \%$ in 2006 , and $13 \%$ in 2007 .

all the sown patches at a site, before the fitting of separate regressions for control and sown forage patches.

\section{Results}

\section{Bumble bee species and visited forage plants}

From a total of 900 transects on the sown and control patches across three years, we observed 9600 bumble bee workers of 10 species. The most abundant were Bombus lapidarius (52\%), B. pascuorum (33\%), B. hortorum (7\%), and $B$. terrestris agg. (7\%), occurring across all eight sites. The remaining sample comprised low numbers of B. pratorum (five sites) and the four declining U.K. Biodiversity Action Plan species (BRIG 2007), $B$. ruderatus (three sites), B. ruderarius, B. humilis, and $B$. muscorum (each at only one site).

We recorded 221 species of plants in flower. Of these, 50 were visited by bumble bees with the sown legume species $T$. pratense, T. hybridum, and L. corniculatus together accounting for $87 \%$ of all visits. Appendix B lists the top 20 forage plants and species-specific preferences of the different bee species. Flower density of visited forage plants differed significantly between years (ANOVA for all years $\chi^{2}=20.3$, df $=2, P<$ 0.001). It was highest in 2005, decreased in 2006 (particularly on sown patches), and increased again in 2007 after some patches had been resown. Within each year, forage density did not differ significantly between sites $\left(\chi^{2}=11.01\right.$ [2005], 9.95 [2006], 10.68 [2007], df $=7$, all $P>0.1)$ or sown patch sizes $\left(\chi^{2}=2.57\right.$ [2005], 3.32
[2006], 3.96 [2007], df = 2, all $P>0.1$ ). However, forage density was significantly higher on the sown forage patches than on controls (Appendix C; $\chi^{2}=15.02$ [2005], 3.98 [2006], 8.33 [2007], $\mathrm{df}=1$, all $P<0.05)$, and there were significant differences across months $\left(\chi^{2}=73.23\right.$ [2005], 23.32 [2006], 15.9 [2007], df $=4$, all $P<0.005$ ) (chi-square approximations after Li and Martin [2002]). Peak flowering occurred during July and August, when the sown patches provided on average 25 (2005), 18 (2006), and 6 times (2007) more forage flowers per unit area than control patches. Hence although forage density was kept relatively constant between sites and patch sizes, we accounted for this temporal variation by including forage density as a covariate in the models for the bee counts.

\section{Bumble bee response to sown forage patches}

After controlling for variation in available forage, the models for total Bombus density and species richness showed that workers had a strong preference for sown forage patches over control areas in each year (Fig. 1), but a significant site $\times$ patch type interaction suggested this response varied depending on the study site (Table 2 ). Eight of the ten species occurred on both control and sown transects, whereas the rare species B. muscorum and $B$. humilis were only recorded visiting sown patches. In terms of cumulative species numbers, the sown patches added on average 1.7 species per site (maximum difference between sown and control $=4$ species). 
TABLE 2. Significance of interactions in models relating the response of bumble bee species and groups to effects of site, patch type (sown/control), local forage density, year, and survey month.

\begin{tabular}{|c|c|c|c|c|c|c|c|c|c|c|c|c|c|}
\hline \multirow[b]{2}{*}{ Interaction terms } & \multirow[b]{2}{*}{$\mathrm{df}$} & \multicolumn{2}{|c|}{$\begin{array}{l}\text { Total, all } \\
\text { Bombus }\end{array}$} & \multicolumn{2}{|c|}{ B. lapidarius } & \multicolumn{2}{|c|}{ B. pascuorum } & \multicolumn{2}{|c|}{ B. hortorum } & \multicolumn{2}{|c|}{$\begin{array}{l}\text { B. terrestris } \\
\text { agg. }\end{array}$} & \multicolumn{2}{|c|}{$\begin{array}{l}\text { Bombus } \\
\text { richness }\end{array}$} \\
\hline & & $\chi^{2}$ & $P$ & $\chi^{2}$ & $P$ & $\chi^{2}$ & $P$ & $\chi^{2}$ & $P$ & $\chi^{2}$ & $P$ & $\chi^{2}$ & $P$ \\
\hline Site $\times$ pa & 7 & 22.64 & 0.002 & 6.50 & 0.48 & 28.09 & $<0.001$ & 13.65 & 0.0 & 16.74 & 0.019 & 45.52 & $<0.001$ \\
\hline Year $\times$ patch type & 2 & 6.80 & 0.033 & 0.81 & 0.69 & 7.65 & 0.022 & 5.88 & 0.053 & 6.46 & 0.039 & 2.08 & 0.35 \\
\hline Year $\times$ forage & 2 & 5.36 & 0.068 & 8.03 & 0.018 & 1.61 & 0.45 & 0.59 & 0.74 & 0.12 & 0.94 & 4.81 & 0.09 \\
\hline Month $\times$ forage & 4 & 24.78 & $<0.001$ & 29.55 & $<0.001$ & 10.14 & 0.038 & 2.99 & 0.56 & 8.71 & 0.069 & 26.32 & $<0.001$ \\
\hline Site $\times$ forage & 7 & 15.06 & 0.035 & 18.45 & 0.01 & 11.20 & 0.13 & 7.29 & 0.39 & 10.84 & 0.15 & 5.22 & 0.63 \\
\hline
\end{tabular}

Notes: Pearson $\chi^{2}$ statistics in bold indicate terms retained in the minimal adequate model; others indicate test statistics for a discarded interaction at the point of deletion from the model. With one exception, any main effect not represented in a significant interaction is itself highly significant $(P<0.001)$; forage was not significantly associated with $B$. hortorum density $\left(\chi^{2}=0.41\right.$, d.f. $=$ $1, P=0.52)$, but all other main effects are retained in all models. Workers of the ecologically similar species Bombus terrestris and $B$. lucorum were recorded as a group, denoted $B$. terrestris agg.

For individual species, the strength of the response to sown patches also varied depending on temporal factors and study site (Table 2, Fig. 1). The significance of the month $\times$ forage interaction confirmed that the effects of increased forage on overall richness and density of most species were greatest in midsummer months (July and August). The strongest positive response to sown patches was from those species preferentially foraging on the sown legume species: B. lapidarius, B. pascuorum, and B. hortorum (Fig. 1; Appendix B). This effect was retained across all years, despite an overall decrease in visitation numbers in 2006 and 2007. A significant site $\times$ patch type interaction for B. pascuorum showed that density was disproportionately higher on sown patches at certain sites. This interaction was not significant for $B$. hortorum or B. lapidarius, suggesting that density was uniformly higher on sown than control patches across all sites, but the significant site $\times$ forage interaction for the latter confirmed that this species' response to forage varied depending on site (Table 2).
Workers of B. terrestris agg. were far less abundant on sown forage patches than the legume specialists, although density of all species was generally similar on control patches (Table 3). There were significant year $\times$ patch type and site $\times$ patch type interactions, with $B$. terrestris agg. showing a positive response to sown patches in 2005, but no differences between patch types in subsequent years (Table 2, Fig. 1). Further exploration of the model for $B$. terrestris agg. showed that density was only significantly higher on sown than control patches in 2005 at site $1(P=0.05)$; in 2006 density was higher on control than sown patches at four sites, significantly so at sites $6(P=0.008)$ and $7(P<$ 0.001 ), and in 2007 was again higher on control than sown patches at four sites, significantly so at site $2(P=$ $0.004)$.

\section{Effects of forage patch size}

Both density and species richness of all Bombus species combined did not differ significantly with size

TABLE 3. Means (and range of means across sites, in parentheses) of predicted values from minimal adequate models showing bumble bee worker density (pooled and by species) and species richness per patch for each patch size and year.

\begin{tabular}{ccccccc}
\hline $\begin{array}{c}\text { Patch size } \\
\text { and year }\end{array}$ & $\begin{array}{c}\text { Total all } \\
\text { Bombus }\end{array}$ & B. lapidarius & B. pascuorum & B. hortorum & $\begin{array}{c}\text { B. terrestris } \\
\text { agg. }\end{array}$ & $\begin{array}{c}\text { Bombus } \\
\text { richness }\end{array}$ \\
\hline $\begin{array}{l}0 \text { ha control } \\
2005\end{array}$ & $2.37(0-6.31)$ & $1.24(0.18-2.5)$ & $0.63(0-2.04)$ & $0.53(0.12-1.11)$ & $0.54(0-1.27)$ & $1.1(0-2.76)$ \\
2006 & $2.86(0-7.62)$ & $0.57(0.08-1.16)$ & $0.96(0-3.13)$ & $0.03(0.01-0.07)$ & $1.05(0-2.44)$ & $0.56(0-1.41)$ \\
2007 & $3.15(0-8.4)$ & $0.36(0.05-0.74)$ & $1.16(0-3.79)$ & $0.16(0.04-0.34)$ & $1.11(0-2.6)$ & $0.74(0-1.87)$ \\
0.25 ha sown & & & & & & \\
2005 & $30.99(7.45-57.8)$ & $17.69(4.41-31.88)$ & $15.96(1.04-40.75)$ & $3.3(0.71-6.37)$ & $1.15(0.15-2.74)$ & $2.08(1.22-3.06)$ \\
2006 & $13.63(3.31-25.7)$ & $8.22(2.05-14.83)$ & $2.12(0.14-5.04)$ & $0.2(0.04-0.37)$ & $0.48(0.06-1.11)$ & $1.06(0.62-1.56)$ \\
2007 & $12.36(2.98-23.22)$ & $5.19(1.1-9.4)$ & $5.59(0.37-14.32)$ & $1(0.22-1.94)$ & $0.92(0.12-2.27)$ & $1.4(0.82-2.07)$ \\
0.5 ha sown & & & & & & \\
2005 & $22.23(3.91-49.72)$ & $10.31(1.5-20.85)$ & $13.23(2.51-25.77)$ & $4.25(0.99-8.87)$ & $0.9(0.26-2.26)$ & $2.13(1.27-2.68)$ \\
2006 & $11.08(1.96-24.96)$ & $4.79(0.7-9.7)$ & $4.27(0.83-8.51)$ & $0.25(0.06-0.52)$ & $1.14(0.33-2.78)$ & $1.09(0.65-1.37)$ \\
2007 & $9.3(1.47-21.54)$ & $2.93(0.37-6.15)$ & $4.58(0.82-9.11)$ & $1.22(0.3-2.7)$ & $1.21(0.29-3.34)$ & $1.44(0.86-1.81)$ \\
1.0 ha sown & & & & & & \\
2005 & $27.57(6.8-57.74)$ & $13.55(1.97-27.4)$ & $8.53(1.91-17.8)$ & $4.18(0.97-8.74)$ & $2.29(0.6-4.85)$ & $2.02(1.5-2.73)$ \\
2006 & $8.13(2.03-17.2)$ & $6.29(0.92-12.74)$ & $1.47(0.34-3.13)$ & $0.25(0.06-0.51)$ & $0.24(0.06-0.49)$ & $1.03(0.77-1.4)$ \\
2007 & $7.21(1.51-15.61)$ & $3.91(0.44-8.08)$ & $3.54(0.82-7.65)$ & $1.22(0.17-2.66)$ & $1.01(0.29-2.34)$ & $1.36(1.01-1.85)$ \\
\hline
\end{tabular}

Note: Predicted values were calculated with forage availability fixed at a constant level of 1000 flower units. 
of the three sown patches $(P>0.05)$. However, significant effects of patch size were found for $B$. lapidarius $\left(\chi^{2}=11.4, \mathrm{df}=2, P=0.003\right), B$. pascuorum $\left(\chi^{2}=63.2, \mathrm{df}=20, P<0.001\right)$, and B. terrestris agg. $\left(\chi^{2}\right.$ $=37.4, \mathrm{df}=20, P=0.011)$. Densities of $B$. terrestris agg. across the three sown patches were low and variable, and the significance of patch size seemed to be governed by a preference for the large patch at site 1 in 2005 . Densities of B. pascuorum were higher on the small $(0.25$ ha) and medium sized ( $0.5 \mathrm{ha})$ patches than the large (1.0 ha) patch at sites where patch type had a significant effect. B. lapidarius also occurred in higher densities on small patches but showed little difference between the medium and large patches (Table 3).

\section{Effects of landscape context and foraging habitat quality}

The proportion of arable land in the surrounding landscape strongly predicted density of all bumble bee species on the sown patches, but not on the unsown controls (Fig. 2; Appendix D). Species richness and densities (especially of the legume specialists) on sown patches were higher in landscapes with high proportions of arable land (e.g., sites 1 and 2). Conversely, richness and densities on sown patches showed a negative relationship with the proportional area of herbaceous forb species, achieving full $(P<0.05)$ or marginal significance $(P<0.08)$ for all species except $B$. lapidarius (shown for B. pascuorum in Fig. 2, for other species see Appendix D). Higher proportions of forbs in the surrounding landscape (e.g., sites 6 and 8) were associated with lower bumble bee densities on the sown patches, and marginally higher densities on controls. The summed area of all key forage plants poorly predicted bumble bee density and richness on sown and control patches $(P>0.05)$ for all species. The proportion of MFCs showed a positive relationship with sown patch densities for all species, unlike that of the other measures of foraging habitat quality. However, this relationship was not significant for the total Bombus group or the two most abundant species $B$. lapidarius and $B$. pascuorum. The proportion of MFCs showed a negative relationship with control patch densities, which was significant for $B$. hortorum $(P<0.001)$. The proportion of MFCs was positively correlated with proportion of arable land $(r=0.65, P<0.001)$.

The lack of a significant relationship between worker density and proportion of arable land on our (non-crop) control patches confirms the low area and variable quality of non-crop habitats at the intensively farmed sites (Table 1). At sites with lower proportions of arable land and larger areas of non-crop habitat and forb cover, control patches were as favorable as sown patches, as reflected in the predicted worker densities (Fig. 2). The exception to this pattern was B. hortorum, for which control patch density was highest at site 2 (Fig. 2c). Here, field margins including that along which the control transects were located supported favorable forage plants (e.g., Ballota nigra) for B. hortorum despite the high proportion of arable land in the landscape. Additional linear regressions showed that the landscape variable most strongly associated with worker density on control patches was the proportion of non-crop boundary habitats $>1 \mathrm{~m}$ wide, such as agri-environmental field margins (e.g., for B. pascuorum $R^{2}=0.768$, slope $=1.81, P=0.004)$. To explore this further we estimated the total number of workers occurring within $1000 \mathrm{~m}$ of each control patch, by scaling up the observed density of workers recorded on control patch transects (total Bombus averaged across months and years) according to our surveyed areas of seminatural habitat. This showed the estimated total population of foragers to be 46 times greater in the landscape with most seminatural habitats (site 6) than the most arable (site 1), and four times greater at site 6 than at site 2 where high quality field margins partially compensated for the high proportion of arable land.

\section{Discussion}

\section{Bumble bee response to sown forage patches}

Our study showed that sowing a mixture of nectarrich forage plants in farmland significantly enhanced the density and species richness of bumble bees, but the strength of this response depended on the composition of the surrounding landscape. The sown legume (Fabaceae) species represented a highly rewarding resource for the longer-tongued bumble bees, including the widespread B. pascuorum and B. hortorum and rarer species of conservation concern such as $B$. humilis, as well as the shorter-tongued $B$. lapidarius, which has previously shown a tendency to forage at Fabaceae (Goulson et al. 2005). We therefore expected them to attract a high concentration of bees relative to surrounding habitat patches. Because resource availability limits the size of bumble bee colonies and larger colonies produce more queens (Muller and Schmid-Hempel 1992, Lopez-Vaamonde et al. 2009), the sown patches are likely to have enhanced colony fitness of these species, although this remains to be tested directly. The weaker response of the shorter-tongued species $B$. terrestris, $B$. lucorum, and $B$. pratorum reflected their visitation to a broader range of plant species. In order to benefit these and other shorter-tongued bee species, conservation flower mixtures should contain a greater diversity of native plant species that is appropriate to the country or pollinator fauna concerned (Isaacs et al. 2009).

The positive effect of sown patches was retained over three years suggesting, together with previous findings (Pywell et al. 2006, Heard et al. 2007), that such additional forage resources can play an important role in enhancing bumble bee abundance. However, there was temporal variation in the bumble bee response both within and between years. Sown patches did not significantly enhance forage availability in all months. This highlights the need to extend the flowering phenology of mixtures sown under AES, by including earlier and later-flowering species or cutting to promote 

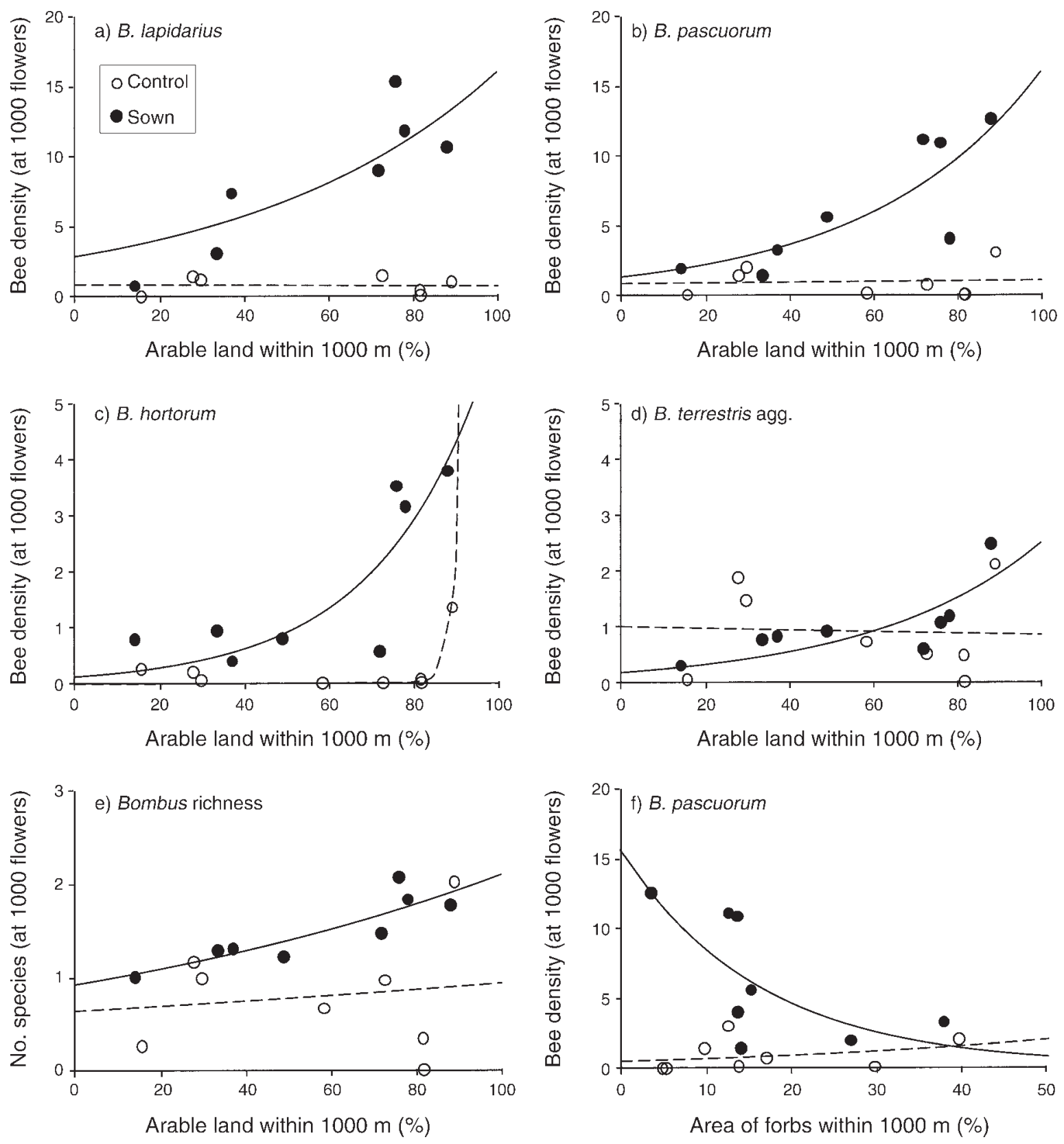

FIG. 2. Example relationships between predicted bumble bee worker density or species richness and landscape variables for control patches (dashed line, open circles) and sown forage patches (solid line, solid circles). Coefficients of determination for linear regressions between density and arable land: (a) B. lapidarius, $R^{2}=0.652, P=0.028$ (sown), and $R^{2}=0.008, P=0.861$ (control); (b) $B$. pascuorum, $R^{2}=0.644, P=0.017$ (sown), and $R^{2}=0.001, P=0.933$ (control); (c) $B$. hortorum, $R^{2}=0.716, P=0.008$ (sown), and $R^{2}=0.918, P=0.001$ (control); (d) B. terrestris agg., $R^{2}=0.552, P=0.034$ (sown), and $R^{2}=0.004, P=0.882$ (control). (e) For Bombus richness vs. arable land, $R^{2}=0.717, P=0.007$ (sown), and $R^{2}=0.018, P=0.754$ (control). (f) For B. pascuorum density vs. forbs, $R^{2}=0.459, P=0.065$ (sown), and $R^{2}=0.076, P=0.510$ (control). Further regression statistics and model results for all species and landscape variables are provided in Appendix D.

successional flowering (Carvell et al. 2004, Isaacs et al. 2009, Memmott et al. 2010), thus also supporting a wider range of other pollinators throughout the season. Increased worker densities do not necessarily reflect increased numbers of bumble bee colonies over time. Indeed, our data showed that, overall, worker density tended to decline over the course of the study. This probably occurred for two reasons. First, the proportion of sown legumes (and hence forage density on the sown patches) declined within two years of sowing, highlighting again the need to consider a broader range of native perennial plants for such mixtures (Isaacs et al. 2009). 
Second, it is likely that the bumble bee colonies and plant communities at our study sites were affected by U.K. weather conditions, which were relatively dry in 2005 but wetter during 2006 and 2007 with significant flooding events during summer 2007 (available online). ${ }^{6}$ Similarly low bee numbers in 2006 and 2007 are reflected by other UK-wide monitoring studies (M. Edwards, personal communication). Therefore we are unable to conclude whether the sown flower mixture enhanced local population persistence from the current data alone. There is a pressing need for studies of changes in the abundance of social bees to take account of effective population size, which can be estimated using molecular methods (e.g., Herrmann et al. 2007, Knight et al. 2009), and this forms the basis of ongoing work by the authors.

\section{Effects of forage patch size}

In terms of the area of forage provided, our data showed a tendency for B. pascuorum and B. lapidarius workers to occur at higher density on 0.25 -ha than 1-ha patches (consistent with the marginal value theorem which predicts that bees should visit a greater proportion of flowers in smaller patches [Goulson 2000]). Hence it appears that 0.25 ha of good quality forage is sufficient to attract large numbers of bumble bees in a typical arable landscape. From a policy perspective therefore, several "smaller" patches of forage $(0.25$ ha equating to a strip of approximately $400 \times 6 \mathrm{~m}$ ) may be more effective than a single large patch or field. Proximity of nests to floral resources has been shown to increase offspring production in both the bumble bee Bombus terrestris (Goulson et al. 2002) and the solitary bee Osmia lignaria (Williams and Kremen 2007), suggesting in addition that introduced forage patches should be distributed across a farm to enhance resource heterogeneity and maximize benefits to bumble bee colonies within foraging range $(\sim 1 \mathrm{~km})$.

\section{Effects of landscape context and foraging habitat quality}

Landscape context (composition and heterogeneity of land use types) in agricultural systems has been shown to have an important influence on species richness and abundance for a range of taxa (bumble bees [Rundlöf et al. 2008]; all bee species [Holzschuh et al. 2007, Williams et al. 2010]; hoverflies [Kleijn and van Langevelde 2006]; arable plants [Roschewitz et al. 2005]). Consistent with these studies, we found that differences in species number between sown forage patches and existing conventionally managed field edges (control patches) increased with the proportion of arable land in the landscape. Overall species richness was relatively similar across our eight study sites. However, different assemblages were reflected in the different regions, with the rarer species showing more localized distributions ( $B$. ruderarius and $B$. humilis were recorded at one site in

${ }^{6}\langle$ www.metoffice.gov.uk $\rangle$ central southern England, while B. ruderatus was recorded at the three sites in eastern England). Despite this variation our data suggest that targeted flower mixtures can benefit a greater proportion of bumble bee species in more intensively farmed landscapes and that even where the proportion of arable land exceeds $85 \%$ in the United Kingdom they can attract the rarer species.

Similarly, our models for worker density showed that sown patches attracted higher densities when surrounded by higher proportions of arable land and lower proportions of herbaceous forbs. This could be due to one or a combination of the following factors: higher nest density within a species' foraging range of the patch; larger colony size; or altered foraging behavior in response to the area and spatial distribution of surrounding habitat patches.

It seems unlikely that nest densities of $B$. lapidarius, $B$. pascuorum, and $B$. hortorum are higher in more intensively farmed landscapes given their requirements for undisturbed nesting sites in non-crop habitat. This is supported by Knight's et al. (2009) study on $B$. pascuorum, which suggests that nest density is related to the proportion of forage resources provided by noncrop areas across the same scale as in our study. Knight et al. (2009) also suggest that high worker abundance at fixed sites is a result of more nests, rather than larger nests, within foraging range, but critically their sample patches were small and more representative of our control areas than of sown patches. In contrast, studies in German agricultural landscapes found no relationship between the proportion of seminatural habitats and worker density of several species on small sample plots (Westphal et al. 2003, 2006) or number of B. pascuorum nests (Herrmann et al. 2007), but a significant positive relationship between mass flowering crop (MFC) area and worker density. They concluded that this higher worker density was due to larger colony sizes resulting from rewarding MFCs, but did not measure either bee density or cover of forage plants on habitats surrounding the focal sampling plots. We cannot exclude the possibility that MFCs had a positive effect on bumble bee colonies in our study landscapes. However, as the dominant flowering crop, winter oilseed rape, was not flowering during most of our sampling visits (with the exception of May), it did not represent a forage resource available to bees visiting the patches. Hence it is not surprising that we found no significant relationship between proportion of MFCs and worker density of the most abundant species on our sown patches. It has also been shown that while such crops may increase worker numbers in the growth phase of the colony cycle, this does not translate to increased numbers of reproductives, even in the common generalist species Bombus terrestris (Westphal et al. 2009).

The data from our control transects strongly suggest that the response of bumble bee workers to introduced forage patches was driven by a lack of alternative forage resources in the most intensively farmed arable areas, 
and subsequent changes in the behavior and distribution of available foragers. This interpretation is of major significance when assessing the benefits to insect pollinators of newly created habitats. Our scaled measure of total number of foragers surrounding the control patches, which was lowest in the most intensively farmed areas, may give a better indication of population size across a landscape than density on small sample patches. Bees have been shown to alter their foraging behavior in response to changes in landscape structure, such as by visiting an increased proportion of flowers in patches in simple landscapes (Steffan-Dewenter et al. 2001). Optimal foraging theory also suggests that bumble bees are likely to forage over larger distances if distant resources are more rewarding and they gain greater rewards per unit time (Heinrich 1979), as would be the case for our sown patches.

A variety of landscape variables have been used to infer context or level of heterogeneity, but to our knowledge, only one other study (from a single U.K. landscape) has surveyed land parcels in such detail as ours, and quantified their value as bee foraging habitats based on absolute area coverage of known plant species (Knight et al. 2009). The lack of a significant relationship between worker density on our sown patches and key forage plants in the landscape could be because other components of seminatural habitats, such as their suitability for nesting, influenced local bumble bee distributions. Furthermore, plant cover may not always correlate with flower availability, as exemplified at study site 8 where forage plant cover was high but grazing of the improved grassland reduced flowering. A more complex model considering these factors, as well as temporal variation in landscape-scale resource availability, may be required. The influence of spatial scale should also be considered. Here we found significant effects of landscape context within $1000 \mathrm{~m}$ on all bumble bee species, as did Holzschuh et al. (2007) for solitary and social bee species, but in some landscapes the larger species such as $B$. terrestris may utilize resources at larger spatial scales, up to $3000 \mathrm{~m}$ (Westphal et al. 2006). Nevertheless, this data set provides the first field estimates of pollinator responses to landscape manipulation and could be used to parameterize the quantitative model recently proposed by Lonsdorf et al. (2009) to test its predictions of wild bee abundance and richness for a different agricultural landscape.

\section{Conclusions}

To conclude, our data, collected over three consecutive years, provide evidence that a targeted AES for pollinators can deliver greater net benefits in more intensively farmed areas, in terms of the number and species richness of bumble bees supported, than in heterogeneous landscapes where other foraging habitats exist and are likely to buffer populations. For relatively widespread species (e.g., B. pascuorum), the data suggest that in such heterogeneous landscapes with $<40 \%$ arable farmland and $>40 \%$ cover of forb species within a radius of $1-2 \mathrm{~km}$, management of existing habitats rather than the creation of new ones may be the better strategy. This complements shorter-term studies that have proposed organic farming and other AES as tools to increase bee diversity in homogeneous landscapes in continental Europe (Tscharntke et al. 2005, Holzschuh et al. 2007) and in the United States (Winfree et al. 2008, Isaacs et al. 2009).

Our study suggests that bumble bee density on conservation flower mixtures is not directly related to the forager population of an area but represents the response of workers to high quality, abundant forage, relative to resource availability elsewhere in the surrounding landscape. It contributes to mounting evidence that the behavior of insect pollinators varies both between and within species according to landscape context and local habitat quality. Further research is required to directly quantify how this translates to variation in foraging ranges and longer term persistence of populations (Keitt 2009). The question also remains as to whether introduced seed mixtures facilitate, or compete with, the pollination of adjacent crops and wild plant species. Finally, while agri-environment schemes are relatively well-developed in Europe, there is still a need for initiatives to better translate science to policy, for example by providing more advice to farmers on sowing and maintaining conservation flower mixtures (Natural England 2010b). Our findings, together with such initiatives, provide a strong evidence base for extending conservation measures to boost declining pollinator populations to a larger number of agricultural landscapes across the globe.

\section{ACKNOWLEDGMENTS}

We thank Norman Carreck, Andrew Martin, Chris Shortall, Jenny Swain, Sarah Hulmes, Lucy Hulmes, Pete Nuttall, Bill Meek, James Peat, Amanda Borrows, and Bill Jordan for fieldwork assistance, GIS mapping, and advice. Thanks to Marek Novakowski (Wildlife Farming Company Ltd.) for guidance on patch establishment and maintenance, and to all farmers who participated in the study. This research was funded by the U.K. Department for Environment, Food and Rural Affairs, and Natural England, Peterborough, United Kingdom.

\section{Literature Cited}

BRIG. 2007. U.K. Biodiversity Action Plan; Report on the species and habitat review. A. Maddock, editor. U.K. Biodiversity Partnership: Biodiversity Reporting and Information Group. 〈http://www.ukbap.org.uk/bapgrouppage. aspx?id=112〉

Carvell, C., W. R. Meek, R. F. Pywell, D. Goulson, and M. Nowakowski. 2007. Comparing the efficacy of agri-environment schemes to enhance bumble bee abundance and diversity on arable field margins. Journal of Applied Ecology 44:29-40.

Carvell, C., W. R. Meek, R. F. Pywell, and M. Nowakowski. 2004. The response of foraging bumblebees to successional change in newly created arable field margins. Biological Conservation 118:327-339.

Carvell, C., D. B. Roy, S. M. Smart, R. F. Pywell, C. D. Preston, and D. Goulson. 2006. Declines in forage availabil- 
ity for bumblebees at a national scale. Biological Conservation 132:481-489.

Corbet, S. A., I. H. Williams, and J. L. Osborne. 1991. Bees and the pollination of crops and wild flowers in the European community. Bee World 72:47-59.

Crawley, M. J. 2005. Statistics: an introduction using R. Wiley, Chichester, UK.

EEC. 1992. Council regulation (EEC) number 2078/92 of 30 June 1992 on agricultural production methods compatible with the requirements of the protection of the environment and the maintenance of the countryside. 〈http://eur-lex.europa.eu/ LexUriServ/LexUriServ.do?uri=CELEX:31992R2078:EN: HTML)

Ellis, J. S., M. E. Knight, and D. Goulson. 2005. Delineating species for conservation using mitochondrial sequence data: the taxonomic status of two problematic Bombus species (Hymenoptera: Apidae). Journal of Insect Conservation 9:75-83.

Goulson, D. 2000. Why do pollinators visit proportionally fewer flowers in large patches? Oikos 91:485-492.

Goulson, D., M. E. Hanley, B. Darvill, J. S. Ellis, and M. E. Knight. 2005. Causes of rarity in bumblebees. Biological Conservation 122:1-8.

Goulson, D., W. O. H. Hughes, L. C. Derwent, and J. C. Stout. 2002. Colony growth of the bumblebee, Bombus terrestris, in improved and conventional agricultural and suburban habitats. Oecologia 130:267-273.

Grixti, J. C., L. T. Wong, S. A. Cameron, and C. Favret. 2009. Decline of bumble bees (Bombus) in the North American Midwest. Biological Conservation 142:75-84.

Hanley, M. E., M. Franco, S. Pichon, B. Darvill, and D. Goulson. 2008. Breeding system, pollinator choice and variation in pollen quality in British herbaceous plants. Functional Ecology 22:592-598.

Heard, M. S., C. Carvell, N. L. Carreck, P. Rothery, J. L. Osborne, and A. F. G. Bourke. 2007. Landscape context not patch size determines bumble-bee density on flower mixtures sown for agri-environment schemes. Biology Letters 3:638641.

Heinrich, B. 1979. Bumblebee economics. Harvard University Press, Cambridge, Massachusetts, USA.

Herrmann, F., C. Westphal, R. F. A. Moritz, and I. SteffanDewenter. 2007. Genetic diversity and mass resources promote colony size and forager densities of a social bee (Bombus pascuorum) in agricultural landscapes. Molecular Ecology 16:1167-1178.

Holzschuh, A., I. Steffan-Dewenter, D. Kleijn, and T. Tscharntke. 2007. Diversity of flower-visiting bees in cereal fields: effects of farming system, landscape composition and regional context. Journal of Applied Ecology 44:41-49.

Isaacs, R., J. Tuell, A. Fiedler, M. Gardiner, and D. Landis. 2009. Maximizing arthropod-mediated ecosystem services in agricultural landscapes: the role of native plants. Frontiers in Ecology and the Environment 7:196-203.

Keitt, T. H. 2009. Habitat conversion, extinction thresholds, and pollination services in agroecosystems. Ecological Applications 19:1561-1573.

Kleijn, D., et al. 2006. Mixed biodiversity benefits of agrienvironment schemes in five European countries. Ecology Letters 9:243-254.

Kleijn, D., and I. Raemakers. 2008. A retrospective analysis of pollen host plant use by stable and declining bumble bee species. Ecology 89:1811-1823.

Kleijn, D., and F. van Langevelde. 2006. Interacting effects of landscape context and habitat quality on flower visiting insects in agricultural landscapes. Basic and Applied Ecology 7:201-214.

Knight, M. E., A. P. Martin, S. Bishop, J. L. Osborne, R. J. Hale, A. Sanderson, and D. Goulson. 2005. An interspecific comparison of foraging range and nest density of four bumblebee (Bombus) species. Molecular Ecology 14:18111820.

Knight, M. E., J. L. Osborne, R. A. Sanderson, R. J. Hale, A. P. Martin, and D. Goulson. 2009. Bumblebee nest density and the scale of available forage in arable landscapes. Insect Conservation and Diversity 2:116-124.

Kremen, C., et al. 2007. Pollination and other ecosystem services produced by mobile organisms: a conceptual framework for the effects of land-use change. Ecology Letters 10:299-314.

Li, B., and E. B. Martin. 2002. An approximation to the F distribution using the chi-square distribution. Computational Statistics and Data Analysis 40:21-26.

Lonsdorf, E., C. Kremen, T. Ricketts, R. Winfree, N. Williams, and S. Greenleaf. 2009. Modelling pollination services across agricultural landscapes. Annals of Botany 103:1589-1600.

Lopez-Vaamonde, C., N. E. Raine, J. W. Koning, R. M. Brown, J. J. M. Pereboom, T. C. Ings, O. Ramos-Rodriguez, W. C. Jordan, and A. F. G. Bourke. 2009. Lifetime reproductive success and longevity of queens in an annual social insect. Journal of Evolutionary Biology 22:983-996.

Memmott, J., C. Carvell, R. F. Pywell, and P. G. Craze. 2010. The potential impact of global warming on the efficacy of field margins sown for the conservation of bumble-bees. Philosophical Transactions of the Royal Society B 365:20712079.

Muller, C. B., and P. Schmid-Hempel. 1992. Correlates of reproductive success among field colonies of Bombus lucorum: the importance of growth and parasites. Ecological Entomology 17:343-353.

Natural England. 2010a. Entry level stewardship: environmental stewardship handbook. Natural England, Peterborough, UK.

Natural England. 2010b. Environmental stewardship update: issue 7. Natural England. 〈http://www.naturalengland.gov. uk/Images/esupdate7_tcm6-16816.pdf $\rangle$

Osborne, J. L., A. P. Martin, N. L. Carreck, J. L. Swain, M. E. Knight, D. Goulson, R. J. Hale, and R. A. Sanderson. 2008. Bumblebee flight distances in relation to the forage landscape. Journal of Animal Ecology 77:406-415.

Pywell, R. F., E. A. Warman, L. Hulmes, S. Hulmes, P. Nuttall, T. H. Sparks, C. N. R. Critchley, and A. Sherwood. 2006. Effectiveness of new agri-environment schemes in providing foraging resources for bumblebees in intensively farmed landscapes. Biological Conservation 129:192-206.

Ricketts, T. H., et al. 2008. Landscape effects on crop pollination services: are there general patterns? Ecology Letters 11:499-515.

Robinson, R. A., and W. J. Sutherland. 2002. Post-war changes in arable farming and biodiversity in Great Britain. Journal of Applied Ecology 39:157-176.

Roschewitz, I., C. Thies, and T. Tscharntke. 2005. Are landscape complexity and farm specialisation related to land-use intensity of annual crop fields? Agriculture, Ecosystems and Environment 105:87-99.

Rundlöf, M., H. Nilsson, and H. G. Smith. 2008. Interacting effects of farming practice and landscape context on bumble bees. Biological Conservation 141:417-426.

Steffan-Dewenter, I., U. Munzenberg, C. Burger, C. Thies, and T. Tscharntke. 2002. Scale-dependent effects of landscape context on three pollinator guilds. Ecology 83:1421-1432.

Steffan-Dewenter, I., U. Munzenberg, and T. Tscharntke. 2001. Pollination, seed set and seed predation on a landscape scale. Proceedings of the Royal Society B 268:1685-1690.

Tilman, D., J. Fargione, B. Wolff, C. D'Antonio, A. Dobson, R. Howarth, D. Schindler, W. H. Schlesinger, D. Simberloff, and D. Swackhamer. 2001. Forecasting agriculturally driven global environmental change. Science 292:281-284.

Tscharntke, T., A. M. Klein, A. Kruess, I. Steffan-Dewenter, and C. Thies. 2005. Landscape perspectives on agricultural 
intensification and biodiversity - ecosystem service management. Ecology Letters 8:857-874.

Westphal, C., I. Steffan-Dewenter, and T. Tscharntke. 2003. Mass flowering crops enhance pollinator densities at a landscape scale. Ecology Letters 6:961-965.

Westphal, C., I. Steffan-Dewenter, and T. Tscharntke. 2006. Bumblebees experience landscapes at different spatial scales: possible implications for coexistence. Oecologia 149:289-300.

Westphal, C., I. Steffan-Dewenter, and T. Tscharntke. 2009. Mass flowering oilseed rape improves early colony growth but not sexual reproduction of bumblebees. Journal of Applied Ecology 46:187-193.

Williams, N. M., E. E. Crone, T. H. Roulston, R. L. Minckley, L. Packer, and S. G. Potts. 2010. Ecological and life-history traits predict bee species responses to environmental disturbances. Biological Conservation 143:2280-2291.
Williams, N. M., and C. Kremen. 2007. Resource distributions among habitats determine solitary bee offspring production in a mosaic landscape. Ecological Applications 17:910-921.

Williams, P. H. 1982. The distribution and decline of British bumble bees (Bombus Latr.). Journal of Apicultural Research 21:236-245.

Williams, P. H., and J. L. Osborne. 2009. Bumblebee vulnerability and conservation world-wide. Apidologie 40:367-387.

Winfree, R., R. Aguilar, D. P. Vazquez, G. LeBuhn, and M. A. Aizen. 2009. A meta-analysis of bees' responses to anthropogenic disturbance. Ecology 90:2068-2076.

Winfree, R., N. M. Williams, H. Gaines, J. S. Ascher, and C. Kremen. 2008. Wild bee pollinators provide the majority of crop visitation across land-use gradients in New Jersey and Pennsylvania, USA. Journal of Applied Ecology 45:793-802.

\section{APPENDIX A}

Map of England and Wales, with a table showing reference codes and locations of the eight study sites (Ecological Archives A021-079-A1).

\section{APPENDIX B}

Percentage of foraging visits across all sites and years by each bee species to each plant species (Ecological Archives A021-079-A2).

\section{APPENDIX C}

Mean flower density of visited forage plants per $\mathrm{m}^{2}$ from transects in each year, along with the range of means across sites (Ecological Archives A021-079-A3).

\section{APPENDIX D}

Relationships between bumble bee worker density, species richness, and selected landscape-context and habitat-quality variables for control and sown patches (Ecological Archives A021-079-A4). 